\title{
Modified toe pulp fillet flap coverage: Better wound healing and satisfactory length preservation
}

\author{
Sang Oon Baek, Hyo Wan Suh, Jun Yong Lee \\ Department of Plastic and Reconstructive Surgery, College of Medicine, The Catholic University of Korea, Seoul, Republic of Korea
}

Background Amputation is commonly performed for toe necrosis secondary to peripheral vascular diseases, such as diabetes mellitus. When amputating a necrotic toe, preservation of the bony structure is important for preventing the collapse of adjacent digits into the amputated space. However, in the popular terminal Syme's amputation technique, partial amputation of the distal phalanx could cause increased tension on the wound margin. Herein, we introduce a new way to resect sufficient bony structure while maintaining the normal length, based on a morphological analysis of the toes.

Methods Unlike the pulp of the finger in the distal phalanx, the toe has abundant teardropshaped pulp tissue. The ratio of the vertical length to the longitudinal length in the distal phalanx was compared between the toes and fingers. Amputation was performed at the proximal interphalangeal joint level. Then, a mobilizable pulp flap was rotated $90^{\circ}$ cephalad to replace the distal soft tissue defect. This modified toe fillet flap was performed in 5 patients.

Results The toe pulp was found to have a vertically oriented morphology compared to that of the fingers, enabling length preservation through cephalad rotation. All defects were successfully covered without marginal ischemia.

Conclusions While conventional toe fillet flap coverage focuses on the principle of length preservation as the first priority, our modified method takes both wound healing and length into account. The fattiest part of the pulp is advanced to the toe tip, providing a cushioning effect and enough length to substitute for phalangeal bone loss. Our modified method led to satisfactory functional and aesthetic outcomes.

Keywords Diabetic foot / Amputation / Surgical flaps / Wound healing

Received: 1 Oct $2017 \bullet$ Revised: 20 0ct $2017 \bullet$ Accepted: 20 Oct 2017

pISSN: 2234-6163 • elSSN: 2234-6171 • https://doi.org/10.5999/aps.2017.01501 • Arch Plast Surg 2018;45:62-68
Correspondence: Jun Yong Lee Department of Plastic and Reconstructive Surgery, Incheon St. Mary's Hospital, College of Medicine, The Catholic University of Korea, 56 Dongsu-ro, Bupyeong-gu, Incheon 21431, Republic of Korea Tel: +82-32-280-5184 Fax: +82-32-280-5556 E-mail: ps.jylee@catholic.ac.kr

\section{INTRODUCTION}

The toe is one of the most vulnerable body parts to ischemia in the human body, due to its insufficient vascular supply compared to other body parts, and also because of experiencing continuous trauma while standing and walking, especially in tight shoes. People with risk factors for vascular compromise, including diabetes, peripheral vascular disease, trauma, infection, and tumors are prone to toe necrosis. There are numerous medical methods of managing skin and soft tissue necrosis in the toes, based on the etiology and extent of necrosis. Amputation is a fundamental treatment for ceasing ongoing necrosis by removing the unsalvageable tissue [1-4]. Various methods have been introduced for the coverage of defects after amputation, 
including local flap coverage, skin graft, and free tissue transfer. Toe fillet local flap coverage is considered to be an ideal surgical method, due to its excellent outcomes and minimal donor site morbidity [5].

The basic concept of conventional toe reconstruction using amputation followed by local flap coverage is to salvage as much bone and soft tissue as possible, in order to prevent adjacent toes from collapsing into the amputated space [6]. It is commonsensical that preserving a longer portion of the toe produces better outcomes functionally and aesthetically. The widely known terminal Syme's amputation procedure is rooted in the aforementioned concept, has the goal of preserving as much length of the toe as possible, and is commonly utilized in clinical practice. In this technique, a toe fillet local flap is used for coverage after amputation. The major shortcoming of this technique is poor wound healing caused by tension around the wound margins, usually due to insufficient bone resection.

Herein, we introduce a modified version of toe fillet flap coverage with a new concept: first, we remove a sufficient bony portion to minimize wound tension, and second, we cover the defect with a fatty pulp area to compensate for the length loss and to provide toe tip cushioning.

\section{METHODS}

\section{Morphological analysis of distal phalangeal toe pulp}

Our approach focused on the abundant amount of pulp in the distal phalanx of the toe. Unlike the pulp in the distal phalangeal area of the finger, the toe has a somewhat teardrop-like shape, with abundant and fatty soft tissue pulp. Thus, the ratio of the vertical length (i.e., the length from the toe dorsum to the plan- tar inflection) to the longitudinal length (i.e., the length from toe tip to the distal interphalangeal joint) in the distal phalanx should be greater in the toes than in the fingers. We calculated and compared the aforementioned ratio between the toes and fingers in a general population of subjects who had suffered no previous trauma and had not undergone any surgical procedures (Fig. 1).

The study was approved by the Institutional Review Board of Catholic University of Korea, College of Medicine (Approve no. 2017-4926-0002). All participants provided written informed consent.

\section{Clinical application and surgical procedures}

The theme of our surgical technique was to resect a sufficient amount of bone and to utilize as much of the abundant pulp of the toe as possible, in an attempt to minimize the wound tension and to compensate for length loss caused by bone resection. From November 2015 to May 2016, 7 modified toe pulp fillet flap procedures were performed in 5 patients. The parameters recorded included age, sex, underlying diseases, clinical presentation, location, size of the defect, surgical procedure, complications, and the preoperative and postoperative length discrepancy (Table 1). Of the 7 toes, 4 were disarticulated at the proximal interphalangeal joint of the toe, 1 at the distal interphalangeal joint of the toe, and the remaining 2 at the interphalangeal joint of the great toe. After disarticulation, all toes were covered using the modified toe pulp fillet method.

The surgical procedures were performed under general or lo$\mathrm{cal}$ anesthesia with a tourniquet for hemostasis. An incision including the necrotic and ulcerated area was made over the dorsal aspect of the toe (Fig. 2). After en bloc excision of the lesion,

\section{Fig. 1. Calculation of the ratios}

Example of calculating the ratio of the vertical axis to longitudinal axis of the left second toe (A) and the left index finger (B) (person no. 3).
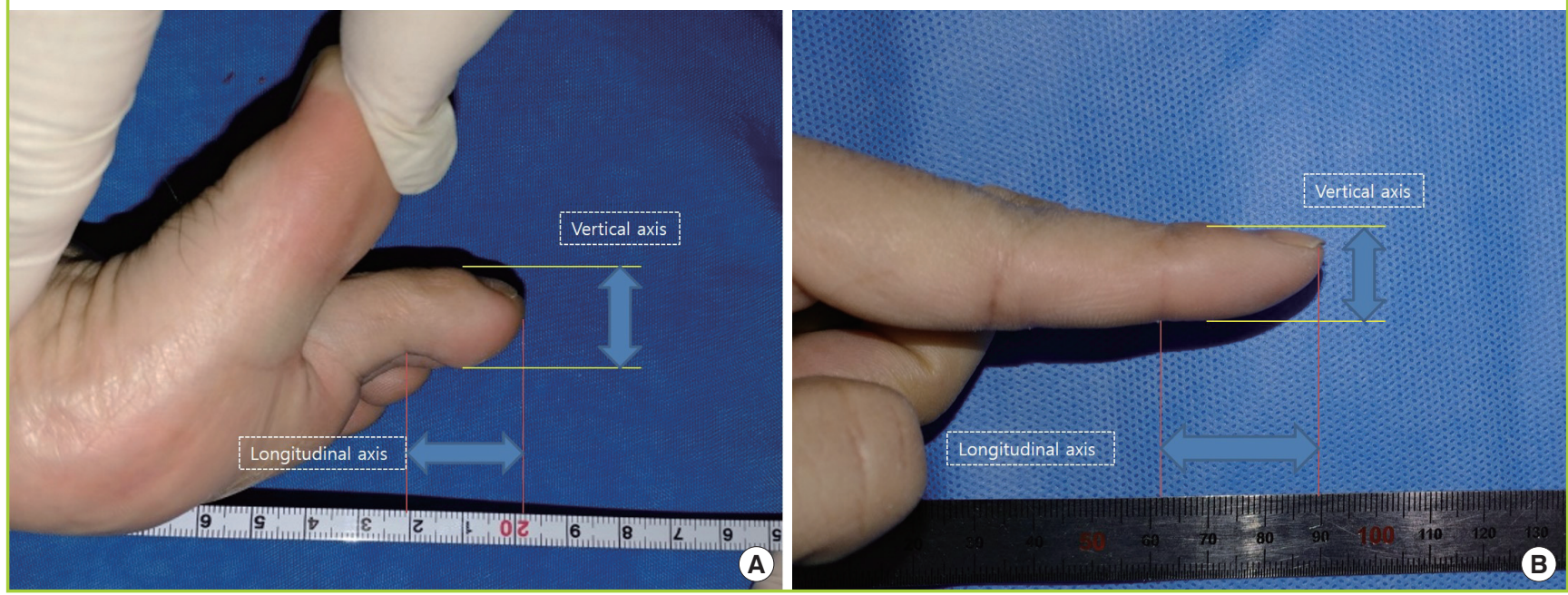


\section{Table 1. Patient data}

\begin{tabular}{|c|c|c|c|c|c|c|c|c|}
\hline $\begin{array}{l}\text { Patient } \\
\text { no. }\end{array}$ & $\begin{array}{l}\text { Toe } \\
\text { no. }\end{array}$ & Age/Sex & $\begin{array}{l}\text { Underlying } \\
\text { diseases }\end{array}$ & Clinical presentation & $\begin{array}{l}\text { Size of } \\
\text { the defect } \\
\text { (cm) }\end{array}$ & $\begin{array}{l}\text { Surgical } \\
\text { procedure }\end{array}$ & Complications & $\begin{array}{l}\text { Length } \\
\text { discrepancy } \\
\text { (cm) }\end{array}$ \\
\hline \multirow[t]{3}{*}{1} & $1-1$ & 74/Female & DM & $\begin{array}{l}\text { DM affecting the foot (necrosis in the distal phalanx } \\
\text { dorsal area of the left second toe) }\end{array}$ & $2 \times 1$ & $\begin{array}{l}\text { Disarticulation at } \\
\text { the PIP joint }\end{array}$ & None & 1 \\
\hline & $1-2$ & & & $\begin{array}{l}\text { DM affecting the foot (necrosis in the distal phalanx } \\
\text { dorsal area of the left third toe) }\end{array}$ & $1 \times 1$ & $\begin{array}{l}\text { Disarticulation at } \\
\text { the DIP joint }\end{array}$ & None & 0.2 \\
\hline & $1-3$ & & & $\begin{array}{l}\text { DM affecting the foot (necrosis in the distal phalanx } \\
\text { dorsal area of the left fifth toe) }\end{array}$ & $1.5 \times 1$ & $\begin{array}{l}\text { Disarticulation at } \\
\text { the PIP joint }\end{array}$ & None & 0.2 \\
\hline 2 & 2 & 65/Male & DM, ASO & $\begin{array}{l}\text { DM affecting the foot (cellulitis progressed to necrosis } \\
\text { in the distal phalanx dorsal area of the left fifth toe) }\end{array}$ & $2 \times 1$ & $\begin{array}{l}\text { Disarticulation at } \\
\text { the PIP joint }\end{array}$ & None & 0.2 \\
\hline 3 & 3 & 71/Male & $\begin{array}{l}\text { DM, HTN, } \\
\text { ESRD, ASO }\end{array}$ & $\begin{array}{l}\text { DM affecting the foot (ulceration with inflamed } \\
\text { granulation tissue on the distal phalangeal lateral } \\
\text { aspect of the right fourth toe) }\end{array}$ & $1.5 \times 1$ & $\begin{array}{l}\text { Disarticulation at } \\
\text { the PIP joint }\end{array}$ & None & 0.9 \\
\hline 4 & 4 & 62/Female & $\begin{array}{l}\text { DM, HTN, } \\
\text { ASO }\end{array}$ & $\begin{array}{l}\text { Third-degree burn on the left great toe (scalding burn, } \\
\text { thick black eschar formation on the medial side of } \\
\text { the left great toe) }\end{array}$ & $3 \times 2$ & $\begin{array}{l}\text { Disarticulation at } \\
\text { the IP joint }\end{array}$ & None & 1.6 \\
\hline 5 & 5 & 66/Female & DM, CAD & $\begin{array}{l}\text { Third-degree burn on the right great toe (contact burn, } \\
\text { ulceration with necrosis on the dorsum of the right } \\
\text { great toe) }\end{array}$ & $7 \times 5$ & $\begin{array}{l}\text { Disarticulation at } \\
\text { the IP joint }\end{array}$ & $\begin{array}{l}\text { Remnant defect, } \\
\text { STSG done }\end{array}$ & 1.8 \\
\hline
\end{tabular}

DM, diabetes mellitus; PIP, proximal interphalangeal; DIP, distal interphalangeal; ASO, arteriosclerosis obliterans; HTN, hypertension; ESRD, end stage renal disease; CAD, coronary artery disease; IP, interphalangeal; STSG, split-thickness skin graft.

\section{Fig. 2. Incision on a necrotic area}

The yellow line indicates the incision made over the necrotic area. The area inside the incision line shows the defect prior to toe pulp fillet flap coverage.

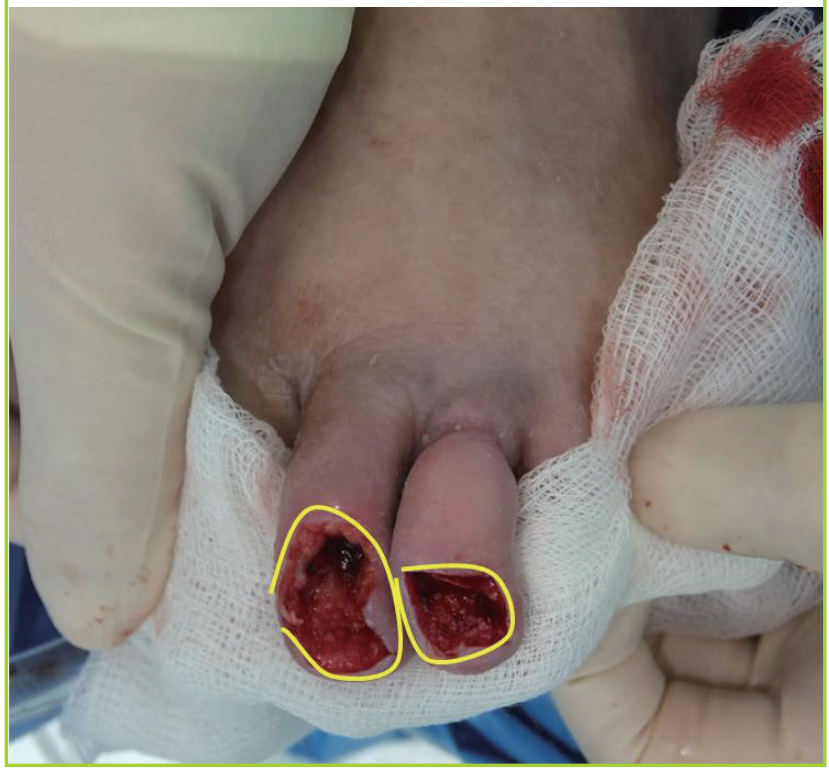

the whole toe pulp flap in the distal phalangeal area was elevated subperiosteally and fully mobilized. Disarticulation at the proximal interphalangeal joint (the interphalangeal joint in the great toes) was then performed, followed by trimming of the flexor and extensor tendons. Bleeding control was performed, and the elevated pulp flap was advanced dorsally covering the defect area. If needed, a Silastic drainage system was placed inside the wound to prevent hematoma or seroma formation. Surgical sutures were removed 2 weeks postoperatively, and no cases of wound dehiscence were observed.

Preoperative and postoperative $\mathrm{X}$-rays were used to calculate the discrepancy between the preoperative and postoperative toe length. Length from the toe tip skin to the interphalangeal joint where disarticulation was performed was measured in the preoperative and postoperative X-rays of each toe. They were compared to calculate the discrepancy.

\section{RESULTS}

\section{Morphological analysis of distal phalangeal toe pulp}

The calculated ratios of the vertical length (i.e., the length from the toe [finger] dorsum to plantar [volar] inflection) to the longitudinal length (i.e., the length from the toe [finger] tip to the distal interphalangeal joint) in the distal phalanx of the toes and fingers of the general population are shown in Tables 2 and 3, respectively. This ratio was significantly greater in the toes (average, 0.90) than in the fingers (average, 0.53), indicating the abundance of pulp tissue in the distal phalanx of the toes.

\section{Surgical outcomes}

The postoperative results after disarticulation followed by toe pulp fillet flap coverage are shown in Figs. 3 to 7. Seven toes in 5 patients, with mean age of 68 years, were included in this study. The cause of the necrosis was a burn in 2 patients, while the other 3 patients had chronic necrosis. The location of the de- 
Table 2. Ratio of vertical length to longitudinal length in the toes

\begin{tabular}{|c|c|c|c|c|c|c|c|c|}
\hline \multirow{2}{*}{ Person } & \multicolumn{2}{|c|}{ Second toe $(\mathrm{cm} / \mathrm{cm})$} & \multicolumn{2}{|c|}{ Third toe $(\mathrm{cm} / \mathrm{cm})$} & \multicolumn{2}{|c|}{ Fourth toe $(\mathrm{cm} / \mathrm{cm})$} & \multicolumn{2}{|c|}{ Fifth toe $(\mathrm{cm} / \mathrm{cm})$} \\
\hline & Right & Left & Right & Left & Right & Left & Right & Left \\
\hline 1 & $1.92 / 1.9(1.01)$ & $1.77 / 2.0(0.89)$ & $2.06 / 2.0(1.03)$ & $1.88 / 2.0(0.94)$ & $2.25 / 2.2(1.02)$ & $1.88 / 1.8(1.04)$ & $1.54 / 1.5(1.02)$ & $1.82 / 2.1(0.87)$ \\
\hline 2 & $1.81 / 1.9(0.95)$ & $1.79 / 1.8(0.99)$ & $1.46 / 1.8(0.81)$ & $1.71 / 2.0(0.86)$ & $1.79 / 1.9(0.94)$ & $1.65 / 2.0(0.82)$ & $1.37 / 1.6(0.86)$ & $2.06 / 1.9(1.08)$ \\
\hline 3 & $1.88 / 2.0(0.94)$ & $1.88 / 1.8(1.04)$ & $1.44 / 1.9(0.76)$ & $1.60 / 1.7(0.94)$ & $1.40 / 1.7(0.82)$ & $1.30 / 1.7(0.76)$ & $1.56 / 1.9(0.82)$ & $1.47 / 1.8(0.82)$ \\
\hline 4 & $1.48 / 1.7(0.87)$ & $1.82 / 2.0(0.91)$ & $1.16 / 1.5(0.77)$ & $1.52 / 2.0(0.76)$ & $1.50 / 1.7(0.88)$ & $1.08 / 1.4(0.77)$ & $1.68 / 2.0(0.84)$ & $1.41 / 1.7(0.83)$ \\
\hline 5 & $1.80 / 2.0(0.90)$ & $1.72 / 1.9(0.86)$ & $1.80 / 2.2(0.82)$ & $1.93 / 2.1(0.92)$ & $1.82 / 2.1(0.87)$ & $1.55 / 1.7(0.91)$ & $1.72 / 2.0(0.86)$ & $1.19 / 1.4(0.85)$ \\
\hline 6 & $1.92 / 2.0(0.96)$ & $1.44 / 1.5(0.96)$ & $1.33 / 1.6(0.83)$ & $1.32 / 1.3(1.02)$ & $1.41 / 1.6(0.88)$ & $1.54 / 1.6(0.96)$ & $1.48 / 1.7(0.87)$ & $1.39 / 1.7(0.82)$ \\
\hline 7 & $2.47 / 2.4(1.03)$ & $2.52 / 2.6(0.97)$ & $2.60 / 2.8(0.93)$ & $1.62 / 2.0(0.81)$ & $2.00 / 2.2(0.91)$ & $1.84 / 2.0(0.92)$ & $1.68 / 1.7(0.99)$ & $1.63 / 1.7(0.96)$ \\
\hline Average ratio & $(0.95)$ & $(0.95)$ & $(0.85)$ & $(0.89)$ & $(0.90)$ & $(0.88)$ & $(0.89)$ & $(0.89)$ \\
\hline $\begin{array}{l}\text { Overall } \\
\text { average ratio }\end{array}$ & $(0.90)$ & & & & & & & \\
\hline
\end{tabular}

Figures in parentheses refer to ratios.

Calculation of the ratio of the vertical length (i.e., the length from the toe dorsum to plantar inflection) to the longitudinal length (i.e., the length from the toe tip to the distal interphalangeal joint) in the lateral view of each toe in normal individuals with no previous trauma or surgical procedures conducted in the foot.

Table 3. Ratio of vertical length to longitudinal length in the fingers

\begin{tabular}{|c|c|c|c|c|c|c|c|c|}
\hline \multirow{2}{*}{ Person } & \multicolumn{2}{|c|}{ Second finger $(\mathrm{cm} / \mathrm{cm})$} & \multicolumn{2}{|c|}{ Third finger $(\mathrm{cm} / \mathrm{cm})$} & \multicolumn{2}{|c|}{ Fourth finger $(\mathrm{cm} / \mathrm{cm})$} & \multicolumn{2}{|c|}{ Fifth finger $(\mathrm{cm} / \mathrm{cm})$} \\
\hline & Right & Left & Right & Left & Right & Left & Right & Left \\
\hline 1 & $2.0 / 3.1(0.65)$ & $1.7 / 3.0(0.57)$ & $1.9 / 3.1(0.61)$ & $1.8 / 2.9(0.62)$ & $1.6 / 3.3(0.48)$ & $1.7 / 2.8(0.61)$ & $1.4 / 2.4(0.58)$ & $1.3 / 2.6(0.50)$ \\
\hline 2 & $1.5 / 3.6(0.42)$ & $1.1 / 2.7(0.41)$ & $1.4 / 2.8(0.50)$ & $1.4 / 2.7(0.52)$ & $1.5 / 2.6(0.58)$ & $1.5 / 2.3(0.65)$ & $1.2 / 2.3(0.52)$ & $1.0 / 2.4(0.42)$ \\
\hline 3 & $1.2 / 2.7(0.44)$ & $1.4 / 2.9(0.48)$ & $1.2 / 2.6(0.46)$ & $1.5 / 2.6(0.58)$ & $1.3 / 2.6(0.50)$ & $1.4 / 2.7(0.52)$ & $1.2 / 2.5(0.48)$ & $1.3 / 2.4(0.54)$ \\
\hline 4 & $1.2 / 3.4(0.35)$ & $1.4 / 2.8(0.50)$ & $1.5 / 2.8(0.54)$ & $1.4 / 2.3(0.61)$ & $1.2 / 2.3(0.52)$ & $0.9 / 2.3(0.39)$ & $1.2 / 2.2(0.55)$ & $0.9 / 2.1(0.43)$ \\
\hline 5 & 2.2/3.7 (0.59) & $1.8 / 3.9(0.46)$ & $2.0 / 2.7(0.74)$ & $1.7 / 3.0(0.57)$ & $1.6 / 3.3(0.48)$ & $1.4 / 2.6(0.54)$ & $1.6 / 2.5(0.64)$ & $1.1 / 2.3(0.48)$ \\
\hline 6 & $1.3 / 2.7(0.48)$ & $1.2 / 2.2(0.55)$ & $1.5 / 2.7(0.56)$ & $1.1 / 2.0(0.55)$ & $1.2 / 2.6(0.46)$ & $1.0 / 2.0(0.50)$ & $1.1 / 2.0(0.55)$ & $0.8 / 2.1(0.38)$ \\
\hline 7 & $2.0 / 4.0(0.50)$ & $1.8 / 3.3(0.55)$ & 1.9/3.0 (0.63) & 1.6/3.2 (0.50) & $1.7 / 3.3(0.52)$ & $1.5 / 2.7(0.56)$ & $1.5 / 2.7(0.56)$ & 1.3/2.2 (0.59) \\
\hline Average ratio & $(0.49)$ & $(0.50)$ & $(0.58)$ & $(0.56)$ & $(0.51)$ & $(0.54)$ & $(0.55)$ & $(0.48)$ \\
\hline $\begin{array}{l}\text { Overall } \\
\text { average ratio }\end{array}$ & $(0.53)$ & & & & & & & \\
\hline $\begin{array}{l}\text { Figures in paren } \\
\text { Calculation of th } \\
\text { distal interphala }\end{array}$ & $\begin{array}{l}\text { heses refer to ra } \\
\text { e ratio of the vert }\end{array}$ & 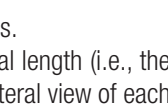 & 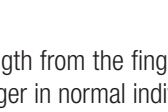 & 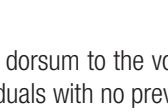 & 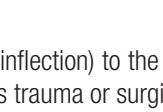 & . & तic & fingertip to the \\
\hline
\end{tabular}

\section{Fig. 3. Patient no. 1 (toe no. 1-1, 1-2, 1-3)}

In a 74-year-old female patient, a diabetic foot with chronic necrosis on the left second, third, and fifth toes. (A) A preoperative photograph. (B) A photograph at a 3-week postoperative follow-up. (C) Preoperative X-ray. (D) Postoperative X-ray. Length discrepancy= $1.0 \mathrm{~cm}, 0.2 \mathrm{~cm}$, and $0.2 \mathrm{~cm}$, respectively.
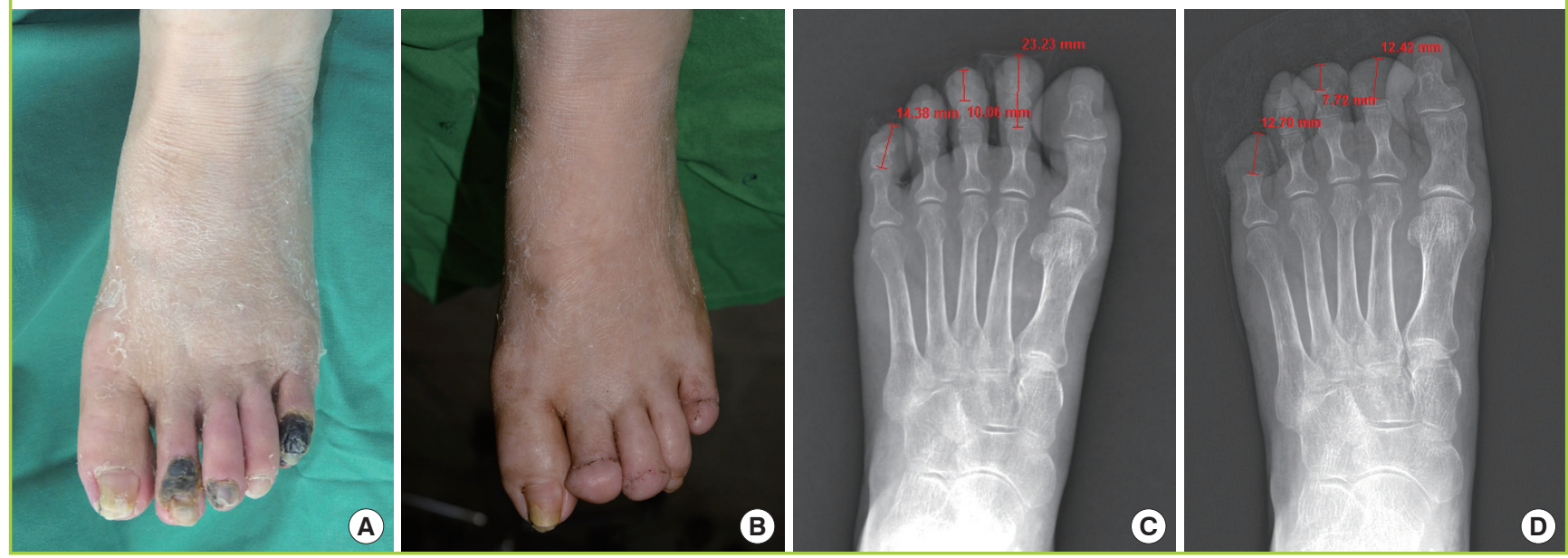


\section{Fig. 4. Patient no. 2}

In a 65-year-old male patient, a diabetic foot with chronic infection on the left fifth toe. (A) A preoperative photograph. (B) A photograph at a 1-month postoperative follow-up.
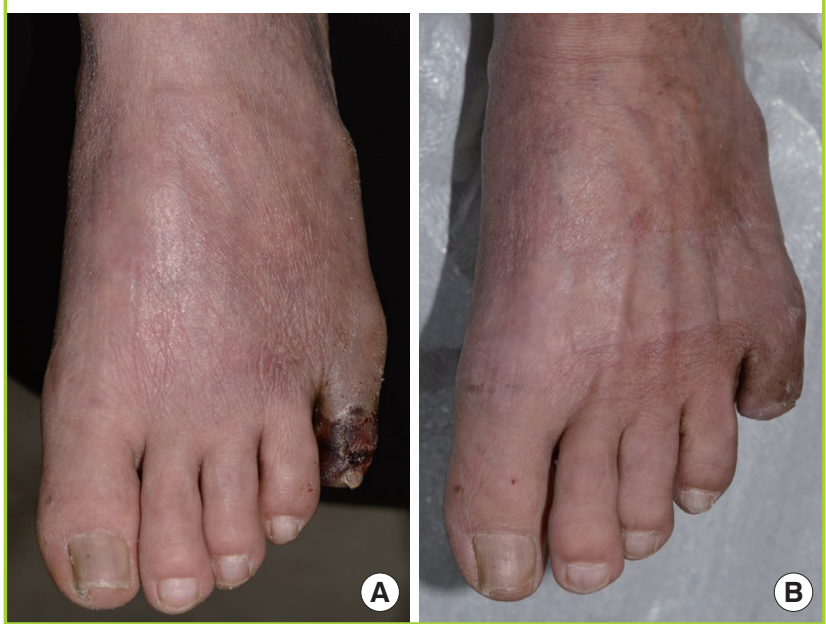

\section{Fig. 5. Patient no. 3}

In a 71-year-old male patient, a diabetic foot with chronic infection on the right fourth toe. (A) A preoperative photograph. (B) A photograph at a 2-month postoperative follow-up.
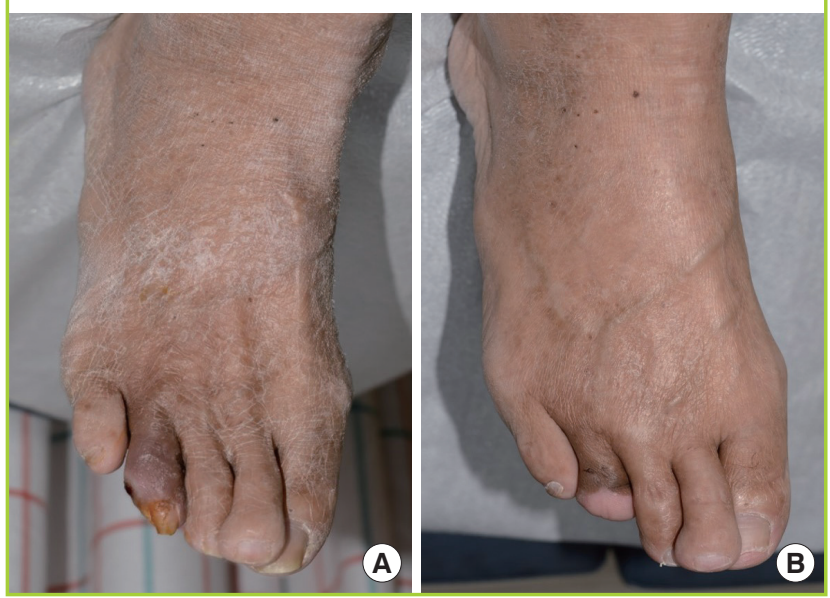

fects was as follows: 2 on the dorsum of the fifth toe, 1 on the lateral aspect of the fourth toe, 1 on the dorsum of the third toe, 1 on the dorsum of the second toe, 1 on the dorsum of the great toe, and 1 on the medial side of the great toe. The average size of the defects was $7 \mathrm{~cm}^{2}$.

In a case with a relatively large $\left(35 \mathrm{~cm}^{2}\right)$ defect on the dorsum of the great toe (patient no. 5, toe no. 5), the defect was not able to be closed by a toe pulp fillet flap alone. Reconstruction was performed with a 2-stage operation (first: toe pulp fillet flap, second: split-thickness skin graft with the right lateral thigh as the donor area) in this case. The defect was successfully covered without wound dehiscence (Fig. 7). Other cases with small defects were reconstructed by a toe pulp fillet flap alone without

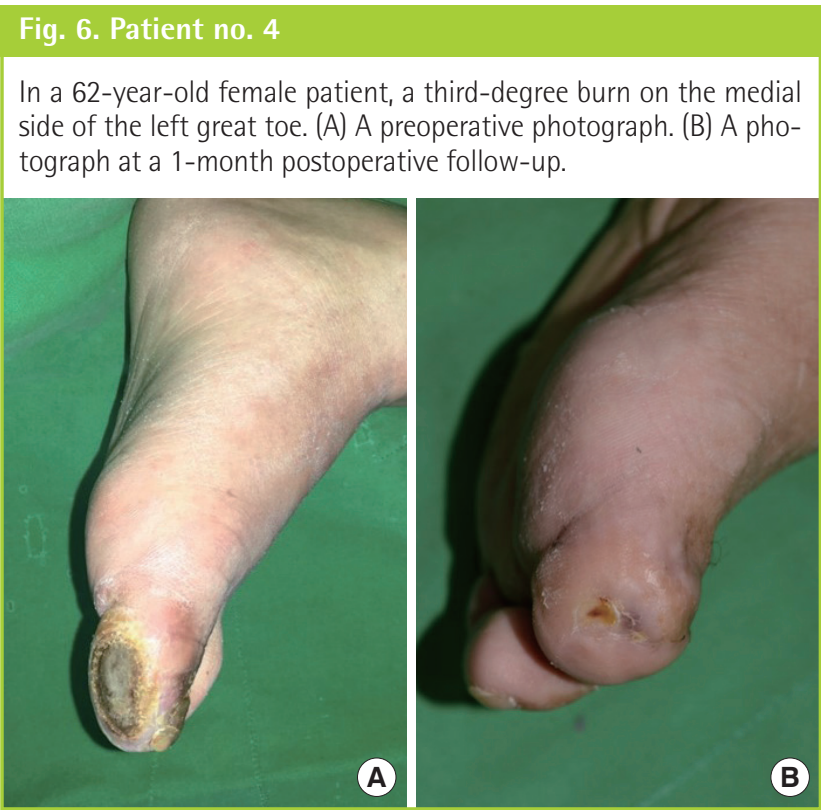

Fig. 7. Patient no. 5

In a 66-year-old female patient, a third-degree burn on the dorsum of the right great toe. (A) A preoperative photograph. (B) A photograph at a 2-month postoperative follow-up.
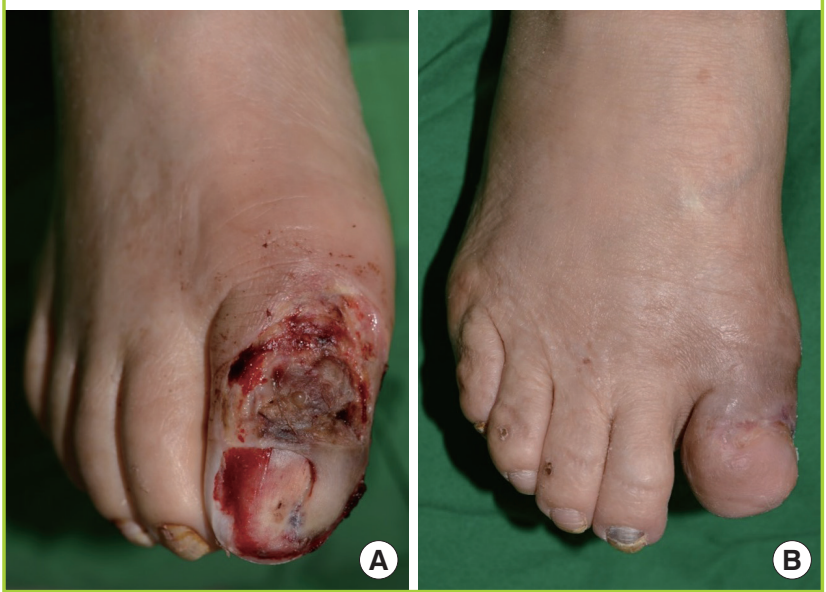

complications.

The preoperative and postoperative length discrepancy of the toes ranged from 0.2 to $1.8 \mathrm{~cm}$ (average, $0.8 \mathrm{~cm}$ ), as shown on the X-rays. The discrepancy was larger in the great toes (average, $1.7 \mathrm{~cm}$ ) than in the other toes (average, $0.5 \mathrm{~cm}$ ).

\section{DISCUSSION}

Amputation is an ancient procedure for treating patients with a non-viable or non-functioning distal limb. Causes of such nonviable tissue in limbs include diabetes, peripheral vascular disease, trauma, chronic infections, tumors, nail deformities, and congenital anomalies [7]. Toes are particularly vulnerable to 
ischemia due to insufficient vascular supply, as a result of being an end organ and being supplied by end arterioles. Moreover, the foot and toe area is prone to continuous trauma while standing or walking, especially when wearing tight shoes. In many cases, amputation is inevitable as the fundamental treatment, and the important issue then becomes the soft tissue coverage. Toe fillet flap coverage is considered to be an ideal surgical method of soft tissue coverage, due to its excellent outcomes and minimal donor site morbidity [5].

Fillet flaps are axially patterned flaps harvested from adjacent non-functioning soft tissue structures. They can be used as pedicled or microvascular free flaps for reconstruction and are a compelling method of reconstruction if enough tissue is available around the defect [8]. Since Alpert and Buncke [9] first introduced the concept of fillet flaps for the coverage of mutilating hand injuries in 1978, they have been widely used as a tool for the reconstruction of distal limbs.

Conventional methods of toe amputation and soft tissue coverage have focused on preserving as much length of the toe as possible, in order to minimize the functional and aesthetic loss. It has been traditionally accepted that restoring as much bone as possible is important for greater support. Too much shortening of the toe can result in adjacent toes collapsing into the amputated space [6]. Thus, length preservation is crucial to prevent such a phenomenon.

Terminal Syme's amputation is a widely used surgical technique that follows the aforementioned principle of length preservation. In terminal Syme's amputation, the nail bed and dorsal soft tissue are excised elliptically. One-third to one-half of the distal phalangeal bone is removed, followed by toe fillet flap coverage for soft tissue reconstruction. Removing only onethird to one-half of the distal phalangeal bone certainly minimizes tissue loss and preserves the maximal limb length $[10,11]$. However, it is evident that insufficient removal of the bony portion could lead to excessive tension on the wound margins and the fillet flap itself after soft tissue coverage. This wound tension can result in poor wound healing, an unstable soft tissue envelope, wound dehiscence, and additional soft tissue necrosis, which may pose a critical problem especially in vascular-compromised patients. Moreover, insufficient soft tissue excision could lead to nail regrowth due to the remnant eponychial fold.

Thus, we deliberately sought to develop a method that would minimize the wound healing problem and simultaneously achieve length preservation. Generally, removing more of a bony portion during amputation would result in reduced wound tension after soft tissue coverage, but length cannot be sufficiently preserved in such circumstances. We focused on the convex, teardrop-like shape of the distal phalangeal area of the toe, which results from an abundant amount of soft pulp tissue. We hypothesized that removing more of a bony portion followed by sufficient advancement and efficient utilization of this abundant pulp would minimize wound tension while preserving sufficient length, since the fatty pulp could provide length when located on the toe tip, substituting for the length loss caused by bone removal.

Bony amputation was performed at the proximal interphalangeal joint level (the interphalangeal joint level in the great toes), which allowed the abundant pulp flap to be completely divided from the bony portion and freely mobilized. The mobilized pulp flap was advanced distally and dorsally, successfully covering the defect area. Wound tension was minimized with an acceptable toe length. The advanced fatty pulp on the toe tip provided a sufficient soft tissue cushion, as well as enough length to substitute for almost one and a half times the amount of phalangeal bone loss that occurs in the terminal Syme's method, as we hypothesized. No significant functional difference between amputation at the distal interphalangeal joint and the proximal interphalangeal joint seemed to exist. The functional and aesthetical outcomes were pleasing.

A major difference between our modified toe pulp fillet flap and the conventional terminal Syme's method is the amount of the bony portion removed during amputation. Our modified method removes more than one and a half times as much of the phalangeal bone of the toe than is removed in terminal Syme's amputation. The length discrepancy between the 2 methods was overcome by advancement of the abundant toe pulp tissue, locating the fattiest part at the toe tip.

In this article, we introduce a modified method of toe pulp fillet flap coverage. The conventional toe fillet flap coverage method focuses on length preservation as the first priority, but it is inevitably accompanied by wound healing problems. In contrast, our method considers the abundant fatty pulp of the distal phalangeal area of the toe, achieving both length preservation and wound healing at the same time. Our modified method led to satisfactory functional and aesthetic outcomes.

\section{CONFLICTS OF INTEREST}

No potential conflict of interest relevant to this article was reported.

\section{PATIENT CONSENT}

The patient provided written informed consent for the publication and the use of their images. 


\section{REFERENCES}

1. Harris WR, Silverstein EA. Partial amputations of the foot: a follow-up study. Can J Surg 1964;7:6-11.

2. Hodge MJ, Peters TG, Efird WG. Amputation of the distal portion of the foot. South Med J 1989;82:1138-42.

3. Larsson U, Andersson GB. Partial amputation of the foot for diabetic or arteriosclerotic gangrene: results and factors of prognostic value. J Bone Joint Surg Br 1978;60:126-30.

4. Brown ML, Tang W, Patel A, et al. Partial foot amputation in patients with diabetic foot ulcers. Foot Ankle Int 2012;33: 707-16.

5. Schade VL. Digital fillet flaps a systematic review. Foot Ankle Spec 2014;8:273-8.

6. Kuntscher MV, Erdmann D, Homann HH, et al. The con- cept of fillet flaps: classification, indications, and analysis of their clinical value. Plast Reconstr Surg 2001;108:885-96.

7. Wagner FW Jr. Amputations of the foot and ankle: current status. Clin Orthop Relat Res 1977;(122):62-9.

8. Kalbermatten DF, Kalbermatten NT, Haug M, et al. Use of a combined pedicled toe fillet flap. Scand J Plast Reconstr Surg Hand Surg 2004;38:301-5.

9. Alpert BS, Buncke HJ. Multilating multidigital injuries: use of a free microvascular flap from a nonreplantable part. J Hand Surg Am 1978;3:196-8.

10. Thompson TC, Terwilliger $C$. The terminal syme operation for ingrown toenail. Surg Clin North Am 1950;31:575-84.

11. Gastwirth BW, Anton VM, Martin RA. The terminal Syme procedure. J Foot Surg 1981;20:95-7. 